Tomasz Je $\dot{z}$

https://orcid.org/oooo-0002-7419-3672

Uniwersytet Warszawski

\title{
Filipa Melanchtona myśl o muzyce i jej rola w kształtowaniu kultury muzycznej humanistycznego Wrocławia
}

Kultura muzyczna szesnastowiecznego Wrocławia pielęgnowana była przede wszystkim w środowiskach kościelnych i szkolnych, które - od czasu wprowadzenia w tym mieście reformacji - tworzyły dopełniający się wzajemnie system powiązań. Ze względu na to, że w kształtowaniu obydwu tych domen niezwykle czynny udział brał Filip Melanchton, zasadnym jawi się pytanie o jego wpływ na funkcjonowanie ośrodków muzycznych nadodrzańskiej metropolii. Odpowiedź na to pytanie przynosi analiza jego piśmiennictwa, powiązanego zarówno z kwestią postrzegania sztuki dźwięku, jak i praktyki muzycznej, uprawianej w ewangelickich kościołach i szkołach miasta.

The musical culture of sixteenth-century Breslau (Wrocław) was cultivated primarily in the Church and school communities, which formed a mutually complementary system of connections since the introduction of the Reformation in the city. Since Philip Melanchthon played an extremely active part in shaping both these domains, the question about his influence on the functioning of Breslau musical centres seems justified. The answer to this question can be found through an analysis of his writings, related both to the issue of the perception of the art of sound and the musical practice followed in the Evangelical churches and schools of the city.

Słowa kluczowe: Filip Melanchton, humanizm, Wrocław, muzyka, edukacja muzyczna

Keyw ords: Philip Melanchthon, humanism, Breslau (Wrocław), music, musical education 
Kultura szesnastowiecznego Wrocławia zawdzięcza wiele aktywności Filipa Melanchtona - wybitnego reformatora ewangelickiego, a zarazem autora jednego z najbardziej udanych systemów edukacyjnych nowożytnej Europy. Liczne dowody tej zależności odnaleziono jak dotąd w wielu różnych obszarach kultury uprawianej w nadodrzańskiej metropolii. Śladów obecności, które pozostawił po sobie praeceptor Germaniae, chcemy jednak także poszukać w mało dotąd z nim kojarzonej domenie kultury muzycznej, która akurat w wieku XVI rozkwitła we Wrocławiu w sposób bezprecedensowy, czyniąc z tego miasta nie tylko stolicę regionu, ale także liczące się centrum europejskie. Fakt, że w dotychczasowej refleksji muzykologicznej Melanchton pozostawał w cieniu Marcina Lutra, jest dodatkowym pretekstem do podjęcia tego typu studiów.

Co ciekawe, zachwiane we współczesnym dyskursie naukowym proporcje między światopoglądem muzycznym Lutra a refleksją Melanchtona na temat muzyki w znacznym stopniu uwarunkowane są doktrynalnymi różnicami pomiędzy obydwoma reformatorami ${ }^{1}$. O ile bowiem myśl o muzyce pierwszego $\mathrm{z}$ nich uległa pewnemu wzmocnieniu na skutek jej skojarzenia z jego poglądami teologicznymi, które pod koniec XVI w. zyskały status oficjalnie uznanej ortodoksji, to poglądy muzyczne drugiego, łączone $\mathrm{z}$ doktryną w pewnej mierze skłaniającą się w stronę kalwinizmu ${ }^{2}$, w analogiczny sposób zostały wyciszone. Zjawisko to uzasadniała ongiś troska o czystość doktryny ewangelickiej, dziś jednak można przyjrzeć się bliżej muzycznemu światopoglądowi głównego autora Confessio Augustana, nawet jeśli dziesięć lat po jej wydaniu zmodyfikował on treść kilku jej artykułów. Potrzebę ponownego zajrzenia do pism Melanchtona uzasadnia nadto oryginalny charakter jego refleksji nad muzyką, składających się na całość nie tylko intelektualnie wyważoną, ale i odnoszącą się w systemowy sposób do zagadnień z zakresu teologii, antropologii, filozofii, edukacji, estetyki oraz muzyki.

Podejmowany tu temat znajduje także swoje uzasadnienie w odniesieniu do obszaru Śląska - w szczególności zaś Wrocławia - którego elity intelektualne zdobywały wykształcenie często pod kierunkiem

1 Por. C. Krummacher, Musik als praxis pietatis. Zum Selbstverständnis evangelischer Kirchenmusik, Göttingen 1994, s. 41.

2 Por. J. Delumeau, Reformy chrześcijaństwa wXVI i XVII w., t. 1: Narodziny i rozwój reformy protestanckiej, tł. J. M. Kłoczowski, Warszawa 1986, s. 182. 
samego Filipa Melanchtona ${ }^{3}$, karierę rozwijały dzięki prowadzonej przezeń korespondencji ${ }^{4}$, a pod bezpośrednim wpływem jego nauk kształtowały swoje poglądy doktrynalne i polityczne $e^{5}$. Wieloletnie kontakty śląskiego duchowieństwa, arystokracji, nauczycieli oraz artystów $^{6}$, intensywnie pielęgnowane między Wrocławiem a Wittenbergą, ukształtowały także specyficzny profil śląskiego ewangelicyzmu, który na przestrzeni pierwszych kilkudziesięciu lat historii bliższy był raczej myśli Melanchtona niż Lutra ${ }^{7}$. Ugodowej naturze wrocławskich mieszczan stanowczo bardziej odpowiadała ireniczna postawa Schwartzerdta, niż bezkompromisowe poglądy teologa z Eisleben, które nad Odrą uznano za powszechnie obowiązujące dopiero pod koniec wieku XVI ${ }^{8}$.

Opisywane tu zjawiska w pewien sposób tłumaczą również zachowawczy charakter liturgii wrocławskich kościołów ewangelickich ${ }^{9}$ i wykonywanej w nich muzyki, która do połowy XVII stulecia obejmowała przede wszystkim tradycyjny repertuar łaciński ${ }^{10}$. Aby jednak odpowiedzieć na pytanie o możliwy wpływ Melanchtona na wrocławskie instytucje kultury muzycznej epoki humanizmu, należy nieco bliżej przyjrzeć się samym źródłom. Są to m.in. listy, które praeceptor Silesiae kierował do reprezentantów elit intelektualnych nowożytnego Wrocławia, czynnie kształtujących różne formy tradycji muzycznych tego miasta. W polu naszego zainteresowania będą również teksty normatywne, regulujące funkcjonowanie lokalnych instytucji życia muzycznego. Przyjrzymy się także tym pismom Melanchtona, które

3 Por. K. Karski, Filip Melanchton w 500. rocznice urodzin, „Myśl Protestancka”, 4, 1997, s. 37.

4 Por. J. Tazbir, Filip Melanchton w pamięci Polaków, OiRwP, 40, 1996, s. 9.

5 Por. A. Modlińska-Piekarz, Doktryna i polityka w tacińskiej poezji biblijnej ślaskich uczniów Filipa Melanchtona, OiRwP, 61, 2017, s. 195-233.

6 Por. M. P. Fleischer, Die Konkordienformel in Schlesien, „Jahrbuch für schlesische Kirchengeschichte", 58, 1979, s. 53-57.

7 Por. J. Harasimowicz, Ślaski luteranizm wieku reformacji-próba charakterystyki, „Śląski Kwartalnik Historyczny Sobótka”, 39, 1984, 4, s. 493-516.

8 Por. K. Garber, Das alte Breslau. Kulturgeschichte einer geistigen Metropole, Köln-Weimar-Wien 2014, s. 50-57.

9 Por. H.-A. Sander, Beiträge zur Geschichte des lutherischen Gottesdienstes und der Kirchenmusik in Breslau. Die lateinischen Haupt-und Nebengottesdienste im 16. und 17. Jahrhundert, Breslau 1937 (Breslauer Studien zur Musikwissenschaft, Bd. 1).

10 Por. T. Jeż, Eacinska twórczość muzyczna w ewangelickim Wroctawiu. Kwestia trwatości tradycji w czasach przemian konfesyjnych, „Barok. Historia - Literatura Sztuka”, 11, 2004, 2 (22), s. 185-205. 
ujawniają jego refleksję na temat muzyki i mogły być znane osobom odpowiedzialnym za wykonywanie muzyki podczas liturgii. Poszukamy też śladów recepcji jego myśli w piśmiennictwie późniejszych pokoleń wrocławskich humanistów, które w jakiś sposób mogły wpłynąć na kształt animowanej w ich kręgach kultury muzycznej.

Chronologiczny przegląd tych źródeł otwiera list Melanchtona z 17 kwietnia 1520 r. do Johanna Hessa, jednego z pierwszych reformatorów Wrocławia (i późniejszego pastora tamtejszego kościoła św. Marii Magdaleny). List ten dotyczy Ambrosiusa Moibana, innego działacza wrocławskiej reformacji (później pastora fary św. Elżbiety), któremu Melanchton zaleca, by w programie nauczania szkolnego uwzględnił postulat rozległej edukacji humanistycznej, sam zaś podjął studia nad zagadnieniem ludzkiej natury ${ }^{11}$. Autor listu nie odnosi się tu wprawdzie bezpośrednio do kwestii muzyki, kładzie jednak mocny fundament pod jej kultywowanie zarówno w dziedzinie edukacji szkolnej, jak i w rozwijanej później refleksji filozoficznej. Nawiązuje przy tym do obecnej już we Wrocławiu tradycji kształcenia humanistycznego, zapoczątkowanej przez śląskich uczniów Konrada Celtisa, w szczególności Wawrzyńca Korwina ${ }^{12}$, którego zasługi na tym polu sam Melanchton chwalił w liście adresowanym najprawdopodobniej do tegoż 19 lutego 1521 r. $^{13}$

Nie wiemy, czy Moiban zastosował się do wszystkich sugestii swego wittenberskiego preceptora, we współpracy z nim wydał jednak w tym samym roku podręcznik gramatyki łacińskiej ${ }^{14}$, a rok później - sztuki

11 Por. „Moibano tam brevi spacio fieri vix potuit nostri copia, tamen commentatus sum cum homine quaedam $\pi \varepsilon p i \pi \alpha i \delta \alpha \gamma \circ \gamma i$ iov, vulgaribus scholis mire cupiens addi rationem condentis carminis, Rhetorica, usumque declamandi, quatenus res permittit. Et quia Philosophicum quid poscebat, censui ipsi sibi scribendum de natura hominis, de qua nondum video digne quiddam scriptum a nostris hominibus. Animantium, gemmarum, herbarum, elementorum, fulminum ac ventorum naturas Plinius suppeditat. De homine nemo, quod sciam, apte scripsit”, Philippi Melanchthonis opera quae supersunt omnia, hrsg. C. G. Bretschneider, Halle 1834-1846 (Corpus Reformatorum, vol. 1-13) (dalej: CR), tu vol. 1, s. $156-157$.

12 Por. G. Bauch, Laurentius Corvinus, der Breslauer Stadtschreiber und Humanist. Sein Leben und seine Schriften, "Zeitschrift des Vereins für Geschichte und Alterthum Schlesiens", 17, 1883, s. 230-302.

13 Por. CR, vol. 1, s. 283.

14 Por. Paedia artis grammatice Ambrosij Moibani opera, in compendie formam redacta ac denuo recognita locupletataque cuius praesidio, pueri latinae linguae rudimenta facilius condiscant, Leipzig 1522, BUWr, sygn. 442131. 
oratorskiej ${ }^{15}$. Wiadomo też, że jako pierwszy wprowadził do wrocławskich szkół naukę języka greckiego ${ }^{16}$. Sam Melanchton wspierał zaś swoją korespondencją kolejnych wrocławskich reformatorów: Sebastiana Hellmanna ${ }^{17}$, Nikolausa Leubela ${ }^{18}$, Johannesa Trogera ${ }^{19}$ i Antona Nigera ${ }^{20}$. Gdy ten ostatni był rektorem szkoły św. Marii Magdaleny, Melanchton rekomendował go do organizacji uniwersytetu w Legnicy ${ }^{21}$; plan ten nie doczekał się jednak realizacji. Niedługo potem wrocławskim szkołom nadano pierwszą ustawę szkolną, której treść nieprzypadkowo wiąże się z tekstem elektorsko-saskiej ordynacji kościelno-szkolnej opracowanej przez Melanchtona również w $1528 \mathrm{r}^{22}$

Ordynacja ta zawiera wiele cennych zaleceń dotyczących muzyki wykonywanej podczas nabożeństw w kościołach i przy okazji nauki w szkołach. Te pierwsze okoliczności ujęte są w rozdziale Von menschlichen Kirchenordenung, gdzie wymieniono dni świąteczne, w czasie których przewidywano bogatszą oprawę liturgii, wykluczając z niej jednak repertuar świecki ${ }^{23}$. Proprium mszalne miało być wykonywane w języku łacińskim, ewentualnie niemieckim tam, gdzie łacina nie była językiem powszechnie zrozumiałym ${ }^{24}$. Jej stosowanie zachowywano

15 Por. Erasmi Roterodami Libellus de constructione octo partium orationis ex Britannia super huc perlatus: ut ex eo pueri bonis in literis optimo compendio bonum profectum faciant, Coloniae 1515, Den Haag, Koninklijke Bibliotek, sygn. 226 E 65; G. Bauch, Geschichte des Breslauer Schulwesens in der Zeit der Reformation, Breslau 1911 (Codex Diplomaticus Silesiae, Bd. 26), s. 36.

16 Por. N. Pol, Jahrbücher der Stadt Breslau, Bd. 3, Breslau 1819, s. 37-38.

17 Por. G. Bauch, Geschichte des Breslauer Schulwesens, s. 43.

18 Por. List do Johanna Hessa, 1 I 1523 r., w: CR, vol. 1, s. 598.

19 Por. List do Johanna Hessa, 19 IV 1524 r., w: ibidem, s. 654-655.

20 Por. List do Ambrosiusa Moibana, 14 VIII 1526 r., w: ibidem, s. 812-813.

21 Por. List do Joachima Cameriarusa, sierpień 1526 r., w: ibidem, s. 811.

22 Unterricht der Visitatoren, an die Pfarrherren im Kurfürstenthum zu Sachssen, Wittenberg 1528, Jena, Thüringer Universitäts- und Landesbibliothek, sygn. HZ: 8 MS 30942(5).

23 „Were auch gut, das sie eintrechtiglich feyerten die Sontage, Annunciationis, Purificationis, Visitationis der reinen Jungfrawen Maria, Sanct Johannis des Teuffers, Michaelis, der Aposteln, Magdalene, dieselben Feste werden denn bereit abgangen und künten nicht bequemlich, alle widder auffgericht werden. Und ynn sonderheit sol man halten, den Christtag, Beschneydung, Epiphanie, die Osterfeyer, Auffart, Pfingsten, doch abgethan, was unchristlich legenden odder gesang darynnen gefunden werden", ibidem, k. G ${ }_{3}$ ver. $-{ }_{4}$ rec.

24 "Etliche singen deudsche, etliche lateinische messen, welchs wir lassen geschehen, doch wird für nützlich und gut angesehen, wo das meiste volck des lateins unverstendig, daselbs deudsche messen zu halten, damit das volck den gesang und anders was gelesen wird, deste das vernemen müge", ibidem, k. $\mathrm{H}_{1}$ rec. 
jednak w najważniejsze święta roku liturgicznego, co nie wykluczało śpiewu niemieckojęzycznych pieśni ${ }^{25}$. Z kanonu przedreformacyjnej liturgii godzin przetrwała praktyka śpiewu jutrzni poprzedzającej poranną mszę świętą (tzw. missa sub aurora ${ }^{26}-\mathrm{w}$ języku łacińskim lub niemieckim - a także nieszporów, które miały być wykonywane w wersji łacińskiej ze względów natury dydaktycznej ${ }^{27}$.

Śpiew repertuaru liturgicznego zaliczano do obowiązków uczniów przykościelnej szkoły, a profil kształcenia obejmował przede wszystkim systematyczną naukę łaciny ${ }^{28}$. Była ona powiązana z edukacją w zakresie praktyki muzycznej, prowadzoną w każdej z trzech kolejnych klas nauczania szkolnego ${ }^{29}$. Autor omawianej ordynacji w rozdziale

25 „An hohen Festen, als Christtag, Ostern, Auffart, Pfingsten, odder der gleichen, were gut, das zur Messe etliche lateynische gesang, die der schrifftgemes, gebraucht würden. Denn es ist ein ungestalt, ymmerdar ein gesang singen. Und ob man schon deudsche gesang wil machen, das sich des nicht ein iglicher vermesse, on die gnade dazu haben”, ibidem, $\mathrm{k}$. $\mathrm{H}_{1}$ ver.; „Mit den Festen, sol es auch fridlich gehalten werden. [--] Die weil es auch ein ungestalt ist, das sie gesang gar gleich sind an allen Festen, were gut, das man an den herrlichsten Festen sünge, die lateynische Introitus, Gloria in excelsis deo, Halleluia, die reinen Sequentz, Sanctus, Agnus dei”, ibidem, k. $\mathrm{K}_{2}$ rec.

26 „Weiter, weil auch an viel enden die alten Ceremonien allenthalben abgethan, und wenig ynn den kirchen gelesen, odder gesungen wird, hat man dieses, wie hernach folget, geordenet. [--] Als nemlich, erstlich mag man alle tag frue ynn der kirchen drey Psalmen singen lateynisch odder deutsch. Und die tage, so man nicht predigt, mag durch einen Prediger eine Lection gelesen werden. [--] Darnach mag die gantze kirche ein deudsch gesang singen, und darauff der Prediger eine Collect lesen", ibidem, k. J J $_{3}$ ver. $-J_{4}$ rec.

27 „Abents were es fein, das man drey vesper psalmen sunge, lateynisch und nicht deudsch, umb der schuler willen, das sie des lateynischen gewoneten. Darnach die reine Antiffen, Hymnos und respons. Darnach möcht eine Lection zu deudsch gehalten werden [--]. Nach der Lection sol man heissen ein vater unser beten. Darnach möcht man singen, das Magnificat, odder Te deum laudamus, odder Benedictus, odder Quicumque vult salvus esse, odder Reyne preces, damit die iugent auch bey der schrifft bleybe. Darnach möcht die gantze kirchen ein deudsch gesang singen, und der Priester endlich die Collecten lesen. Inn kleinen flecklen, da nicht schüler sind, ist nicht von nöten, das man teglich singen. Es were aber gut, das sie etwas süngen, wenn man predigen wil", ibidem, k. J $\mathrm{J}_{4}$ rec.-ver.

28 „Erstlich, sollen die schulmeister vleis ankeren, das sie die kinder allein lateynisch leren, nicht deudsch odder grekisch, odder ebreisch, wie etliche bisher gethan, die armen kinder mit solcher manchfeltickeit beschweren, die nicht allein unfruchtbar, sondern auch schedlich ist", ibidem, k. $\mathrm{L}_{3}$ ver.

29 „Vom ersten hauffen. [--] Diese kinder sollen auch zu der musica gehalten werden, und mit den andern singen, wie wir darunden, will Gott, anzeigen 
Von Schulen przewidywał dzielenie rozkładu zajęć uczniów szkoły między naukę w szkole (m.in. właśnie muzyki) i czynne uczestnictwo w nabożeństwach. Pragmatyczne powiązanie edukacji uczniów $\mathrm{z}$ ich udziałem $\mathrm{w}$ liturgii uzasadnia też sugerowany przez Melanchtona dobór psalmów, zalecanych jako szczególnie użyteczny materiał służący formacji religijnej uczniów ${ }^{30}$. W kontekście poczynionych wyżej obserwacji należy domniemywać, że nie tylko uczyli się oni tych psalmów na pamięć, ale także śpiewali je w czasie liturgii, co potwierdza obecność tych tekstów w najbardziej typowych cyklach nieszpornych i liczne ich opracowania muzyczne w rękopisach pochodzących z tej części Europy.

Obydwa te zjawiska poświadczają zresztą źródła muzyczne proweniencji wrocławskiej ${ }^{31}$, a także ustawa szkolno-kościelna przyjęta przez magistrat tego miasta 25 listopada $1528 \mathrm{r}^{32}$ Jej autorem był Johannes Metzler, również pozostający pod silnym wpływem Melanchtona, o czym świadczą liczne filiacje treści ustawy z przywołaną wyżej ordynacją. Podobnie jak w dokumencie kierowanym do przełożonych kościołów i szkół Saksonii, również w jego wrocławskim odpowiedniku zaakcentowano latynistyczny profil edukacji ${ }^{33}$

wöllen. [--] Von dem andern hauffen. [--] Die erste stunde nach mittag teglich, sollen die kinder ynn der musica geübet werden, alle, klein und gros”, ibidem,

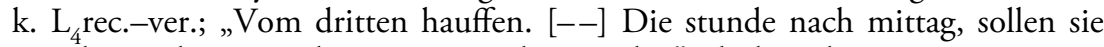
mit den andern ynn der Musica geübet werden”, ibidem, k. $M_{3}$ rec.

30 „Daneben sol der schulmeister den knaben etliche leichte Psalmen fürgeben, aussen zu lernen. Inn welchen begriffen ist, eine summa eines Christlichen lebens. Als, die von Gottes forcht, von glauben, und von guten wercken, leren. Als der hundert und ellfft Psalm, Wol dem man, der Gott förcht. Der vier und dreissigst. Ich will den Herrn loben allezeit. Der hundert und acht und zwentzigst, Wol dem der den Herrn förcht, und auff seinen wegen gehet. Der hundert und funff und zwentzigst Psalm, Die auff den Herren hoffen, werden nicht umbfallen, sondern ewig bleiben, wie der berg Zion. Der hundert sieben und zwentzigst Psalm, Wo der Herr nicht das Haus bawet, so erbeyten umb sonst die daran bawen. Der hundert und drey und dreyssigst Psalm, Siehe wie feyn und wie lieblich ists, das brüder miteinander wonen. Und etliche der gleichen leichte und klare Psalmen, welche auch sollen auffs kürtzist und richtigst ausgelet werden, damit die kinder wissen, was sie daraus lernten und da suchen sollen", ibidem, k. $\mathrm{M}_{2}$ rec.-ver.

31 Por. E. Bohn, Die musikalischen Handschriften des XVI. und XVII. Jahrhunderts in der Stadtbibliothek zu Breslau, Breslau 1890.

32 Schulen und Kirchenordnung des Rathes der Stadt Breslau. Współczesna edycja tego dokumentu zob. G. Bauch, Geschichte des Breslauer Schulwesens, s. 73-77.

33 „Alle Knaben, die zur Unterweisung und Zucht gegeben werden, sollen zuerst dem Schulmeister überantwortet und von diesem in sein Register verzeichnet werden. 
i obowiązek obecności uczniów w czasie liturgii ${ }^{34}$. W stosunku do ordynacji saksońskiej ustawa wrocławska wprowadza więcej rozwiązań praktycznych, dotyczących np. zakresu obowiązków personelu szkoły i kościoła, jak również wynikającej stąd synergii obydwu tych instytucji, tworzących prawdziwie symbiotyczny układ.

Szczególną rolę w tym systemie pełnili stażyści (tzw. Schreiber), których zadaniem było wspomaganie uczniów w nauce i śpiewanie muzyki liturgicznej w kościele (dlatego też określano ich później mianem Choralisten $)^{35}$. Wykonania te prowadził sygnator, często będący jednocześnie nauczycielem (m.in. muzyki ${ }^{36}$ ). Z racji tej ostatniej funkcji powierzano mu odpowiedzialność za śpiew chóru złożonego z jej uczniów (Chorknaben). Obydwa zespoły dzieliły się repertuarem wykonywanym podczas mszy odprawianych w dni świąteczne, a także jutrzni i nieszporów, składających się z łacińskich psalmów, antyfon i responsoriów ${ }^{37}$.

Der Schulmeister soll dann darauf achtgeben, daß die Knaben fleißig und treulich unterwiesen und besonders, lateinisch in der Schule mit einander zu reden, vornehmlich die Primarii und Secundarii angehalten werden”, ibidem, s. 73. „Damit auch der Chor in beiden Pfarren um so stattlicher gehalten werden möge, hat der Rat verordnet, daß fortan keinem Knaben in dieser Stadt vor den Türen zu betteln oder zu singen gestattet sein soll, er sei denn ein Schüler, besonders da nun fortan alle einheimischen Kinder in gleicher Weise umsonst unterrichtet werden und hierbei niemand auf seine Armut verweisen kann. Und diese Knaben, die in der Stadt betteln werden, sollen in der Schule treulich wie die andern unterwiesen werden und zu Chore gehen, dem Schulmeister in der Schule und dem Signator im Chore in allem gehorsam sein, besonders aber die Verstorbenen mit dem angeordneten Gesange bestatten helfen”, ibidem, s. 74. „Da aber der Chor in der Kirche gehalten werden muß, mag jeder Schulmeister sechs Schreiber, die fromm und zum Lernen geschickt sind, und sich nach Gebühr halten, aufnehmen. [--] Weil nun von diesen sechs Schreibern zwei Auditores sein sollen, sollen allemal fünf wöchentlich dem Signator den Chor in der Kirche zu halten, nämlich Messe und Vesper zu singen, schuldig sein. Und der eine Auditor soll unterdes die Elementarios unterweisen. Die andern vier Schreiber, die nicht Auditores sind, sollen mit der Kommunion, wenn das nicht unter der Messe oder Vesper ist, zu gehen schuldig sein. Unter der Messe und der Vesper dürfen sie nicht mitgehen, sondern nur der Kirchenknecht mit einer Laterne und einer Glocke”, ibidem, s. 74-75.

36 „Es soll auch nach Anordnung der Herren Doktoren den Knaben alle Wochen eine Lektion in der Musik gelesen werden und sie sollen im Singen treulich und fleißig wie in den andern, nötigen Künsten unterwiesen und geübt werden”, ibidem, s. 75 .

37 „Der Signator soll als Lohn auf ein Jahr 6 Mark haben. Dafür soll er in der Woche Vesper und Messe singen und an dem Sonntage und den Feiertagen, die ihm der Pfarrer angibt, soll er Metten, Vesper und Messe singen und daneben einige Antiphonen und Responsoria oder sonst deutsche Lieder, die ihm angezeigt 
Repertuar Chorknaben obejmował oczywiście także pieśni w języku niemieckim, Choralisten śpiewali zaś przede wszystkim utwory łacińskie, związane nie tylko z liturgią mszy, jutrzni i nieszporów, ale również takich form liturgii, jak Horae de Beata Maria Virgine, Horae de passione Domini czy responsorium Tenebrae factae sunt $t^{38}$.

Jeśli przyjmiemy, że zachowawczy profil repertuaru wrocławskich kościołów uzasadnia pokrewieństwo przytoczonych dokumentów, to związki między doktryną Melanchtona a praktyką muzyczną wrocławskich kościołów potwierdzają stosowane w nich formuły zobowiązań, podpisywane przez choralistów nie tylko kościołów św. Elżbiety i św. Marii Magdaleny, ale także innych ewangelickich świątyń miasta $^{39}$. Kultywowanie przedreformacyjnych zwyczajów liturgicznych musiało się zresztą cieszyć życzliwością wrocławskich biskupów, którzy (przynajmniej w pierwszych dekadach reformacji) przyglądali się jej ze sporą dozą tolerancji. O klimacie tych czasów dobitnie świadczy list gratulacyjny Melanchtona, dołączony do okolicznościowej publikacji Moibana, którą ten ostatni dedykował nowo wybranemu biskupowi Balthasarowi von Promnitz ${ }^{40}$. W datowanym na

werden. [--] Am Sonnabend, Sonntag und andern Feiertagen, wenn man in der Schule nicht liest, sollen alle Knaben zur Messe und zur Vesper in den Chor gehen, dort singen und nicht vor der angeordneten Zeit aus dem Chore laufen. Darauf soll der Signator fleißig achtgeben und die Herauslaufenden vermerken und seinerzeit angemessen bestrafen", ibidem, s. 74-75.

38 Por. H.-A. Sander, op. cit., s. 14-31.

39 Por. Schreiber oder Choralisten bei dem hl. Geist und St. Bernhardin. Ihre Zusagung und Verplichtung: „2. Sie sollen vor allen Dingen die Lehre von Gott, so in dem kleinen und großen Catechismo Luthers und in dem Examine theologico Philippi Melanchthonis begriffen ist, fleißig lernen und daneben täglich in der Bibel fleißig lesen, daß sie den Text gemein machen. [-- 6. [--] Am Sonntage und an andern Feiertagen und, wenn man sonst in der Kirche pfleget zu singen, in den beiden zum heiligen Geiste und Sankt Bernhardin, vor und nach der Predigt, sollen sie den Gesang befördern helfen. [--]. 7. Und weil es in diesem Hospital bisher bräuchlich gewesen, daß man den armen Leuten des Morgens und Abends aus der heiligen Schrift gelesen, so sollen sie auch forthin ihnen täglich daraus vorlesen, mit ihnen beten und die geistlichen Lieder Gott dem Herrn zu Lob und Ehren singen helfen. Auch, wenn man isset, sollen sie mit den armen Leuten das Benedicite und Gratias sprechen und die gewöhnlichen Lieder singen. Auch, wenn gütige Leute dem Armut ihr Almosen mitteilen und sie zurstelle sind, sollen sie den Gesang befördern helfen"; cyt. za: G. Bauch, Geschichte des Breslauer Schulwesens, s. 133.

40 Por. Ad Clariss. Principem, eundemque Reverendiss. D. D. Balthasarem Episcopum Vratislaviens: etc. Epistola Gratulatoria. Autore Ambrosio Moibano Parocho Vratislavien: Adiecta est et Epistola Phil. Melan. ad eundem Episcopum, Wrocław 1541, BUWr, sygn. 303030. 
1 maja 1541 r. piśmie praeceptor Wratislaviae chwali łagodne usposobienie hierarchy i roztropną opiekę nad podległą mu diecezją; docenia także jego zainteresowanie sztuką i wieńczy swój list szczerymi życzeniami pokoju, ujętymi w formie muzycznej (nieprzypadkowo) metafory ${ }^{41}$.

O kształcie kultury humanistycznego Wrocławia decydowali jednak nie tylko reprezentanci elit kościelnych, ale także przełożeni instytucji edukacyjnych. Ważną rolę odegrał tu wspomniany wyżej Johannes Metzler, nauczyciel szkoły św. Elżbiety i autor ustawy szkolno-kościelnej z 1528 r. Utrzymywał on bliskie kontakty z Melanchtonem, a w programie nauczania wykorzystywał jego pisma ${ }^{42}$; ten ostatni chwalił go zaś za organizację kształcenia w szkołach wrocławskich $^{43}$. Uznaniem Schwartzerdta cieszył się też Andreas Winkler, który pod jego kierunkiem odbył studia magisterskie, wyróżnione wydaną drukiem laudacja promotora ${ }^{44}$. Winkler był wieloletnim przełożonym szkoły św. Elżbiety i wprowadzał w praktykę zalecenia ustawy szkolnej Metzlera, w 1538 r. uruchomił zaś własną oficynę wydawniczą, która służyła przede wszystkim celom dydaktycznym ${ }^{45}$.

41 Por. „Baldassaro a Promnitz Episcopo Vratislaviensi. S. D. Reverende Domine. Postquam intellexi, te ad hoc fastigium evectum esse, gratulabar Ecclesiae talem gubernatorem, cuius moderationem iudicabam in his dissidiis Ecclesiasticis, salutarem Ecclesiae fore. Noram enim et animum tuum natura placidum, et assiduitatem in optimarum artium studiis, et audiebam, te non abhorrere $a b$ eorum sententiis, qui censent sine saevitia moderatis rationibus, in Ecclesia concordiam constituendam esse. [--] Magnum et salutare Dei munus est talis Pastor, qui in tantis tenebris et dissidiis, et doctrinae lumen in Ecclesia accendere, et dissipatum gregem revocare ad piam Concordiam studet, ut hymnum illum cum Angelis pariter omnes canant: Gloriam Deo, et terrae pacem, et laetitiam hominibus. Haec scripsi bono et simplici studio, quae si intellexero tibi grata fuisse, saepius ad te iisdem de rebus scribam. Bene et feliciter vale. Cal. Maii. Ratisbonae 1541”, CR, vol. 4, s. 250-251.

42 G. Bauch, Geschichte des Breslauer Schulwesens, s. 55-59.

43 „Gratulor reipublicae vestrae, quod scholam habet bene constitutam. Tibi etiam hanc virtutem ac laudem gratulor, quod ornare et tueri literas authoritate tua studes. Itaque precor Deum, ut ad reipublicae salutem diu tue servet et incolumem", List do Johannesa Metzlera, 30 IV 1534 r., w: CR, vol. 4, s. 1024.

44 Por. Oratio Philip. Melanch. dicta ab ipso cum decerneretur gradus magisterii $D$. Andreae Winclero Vratisla. et alijs quibusdam bonis et doctis viris anno M.D. XXXV. die Aprilis 14, Strasbourg [1535], Jena, Thüringer Universitäts- und Landesbibliothek, sygn. 8 Phil.IX,24.

45 Por. M. Burbianka, Andrzej Winkler - drukarz wroctawski XVI wieku, „Roczniki Biblioteczne", 4, 1960, s. 329-445, 636-638. 
Obok podręczników łacińskiej gramatyki i syntaksy autorstwa Melanchtona ${ }^{46}$ oraz poprzedzonych jego przedmowami edycji komedii Terencjusza i ód Horacego ${ }^{47}$ Winkler wydał nawet traktat poświęcony teorii muzyki ${ }^{48}$. Autorem tego dziełka był sygnator elżbietańskiej fary, Vergilius Haug, który nadał temu podręcznikowi formę pytań i odpowiedzi, stosowaną w ówczesnych katechizmach.

Winkler publikował zresztą także własne katechizmy, idąc śladem Moibana, który pierwsze publikacje tego typu, np. Catechismi capita decem, wydał jeszcze w Wittenberdze, opatrując je przedmowami swego preceptora ${ }^{49}$. Druk ten ułożono $\mathrm{w}$ formie dialogu prowadzonego przez Kiliana (syna Joannesa Metzlera) i Elisabeth (córkę Andreasa Winklera). Po objaśnieniu dekalogu przytoczono kilka łacińskich modlitw, m.in. psalm Deus miseratur nostri, którego muzyczne opracowania odnajdujemy w wielu wrocławskich rękopisach ${ }^{50}$. Kolejna wersja katechizmu Moibana, drukowana już przez Winklera $^{51}$, zawiera jeszcze więcej modlitw dla wrocławskich uczniów (niektóre z nich były z pewnością śpiewane). Podobny repertuar zawierają wielokrotnie wznawiane zbiory sentencji, wydawane przez kolejnego właściciela wrocławskiej oficyny Winklera, Kryspina Scharffenberga.

46 Por. Elementa latinae grammatices ab ipso autore recognita. Philip. Melancht., Wrocław 1539, BUWr, sygn. 372172; Syntaxis Philippi Melanchtonis emendata et aucta ab autore, Wrocław 1540, BUWr, sygn. 372174.

47 Por. P. Terentii comoediae, iuxta doctissimorum virorum recognitionem, quam diligentissimae excusae. [--] Accesserunt praeterea argumenta. Philippi Melanch. et Rivij castigationes, scholia cum omnium fere scenarum argumentis, quae prolixi commentarij vice esse possunt, Wrocław 1540, BUWr, sygn. 373119; Selectiores Horatiani Operis Odea ad formandos mores tum cognitu utiles, tum perquem iucundae. Adiecta sunt aliquot pia epigrammata ex varijs poetis Christianis, Wrocław 1542, BUWr, sygn. 336073.

48 Por. Erotemata musicae practice ad captum puerilem formata, Virgilio Haug autore, Wrocław 1541, Bruksela, Bibliothèque royale de Belgique, sygn. A-G ${ }_{8}$.

49 Np. Catechismi capita decem: primum quibusdam thematis deinde etiam colloquiis puerilibus illustrata, iuventuti Wratislaviensi proposita. Ambrosius Moibanus. Accessit et puellae cuiusdam oratiuncula in nativitate Ihesu Christi publice dicta. Cum prefatione Phil. Mel., Wittenberg 1538, BUWr, sygn. 301174.

50 E. Bohn, op. cit., s. 207.

51 Catechismi capita decem: primum quibusdam thematis deinde etiam colloquiis puerilibus illustrata, iuventuti Wratislaviensi proposita. Ambrosius Moibanus. Accessit et puellae cuiusdam oratiuncula in nativitate Iesu Christi publice dicta. Cum prefatione Philippi Melanch., Recognita omnia ab ipso Authore, Wrocław 1546, Berlin, Staatsbibliothek Preussischer Kulturbesitz, sygn. Ep 3492. 
Obok tekstów służących formacji gimnazjalistów pojawiają się tu pieśni oraz hymny na różne pory dnia i roku liturgicznego ${ }^{52}$.

Przytoczone dotąd źródła zgodnie poświadczają, że muzyka była we Wrocławiu ważnym elementem wszechstronnego modelu kształcenia, orientowanego ideałami humanistycznymi. Sztuka dźwięku zajmowała jednak nie tylko istotne miejsce w animowanej przez Melanchtona dydaktyce, odgrywała również znaczącą rolę w uprawianym przezeń piśmiennictwie. Korzenie jego myśli o muzyce wyrastają z tradycji greckiego antyku, którego treści poddane zostały teologicznej interpretatio christiana, typowej dla wielu reformatorów XVI stulecia. Sama muzyka postrzegana tu bywa nie tylko jako metafora kultury, ale uznana jest za jej pełnoprawny język, niezbędny zarówno dla liturgii, jak i pedagogiki. Melanchton zręcznie wiąże refleksję teoretyczną z uwagami o charakterze praktycznym, odnoszonymi czasem do sonosfery ówczesnego Wrocławia ${ }^{53}$. Szczególne miejsce wśród sztuk wyzwolonych przyznaje zaś muzyce, co wynika z użyteczności tej sztuki w oddziaływaniu na etykę i emocje ${ }^{54}$.

52 Por. „Cantiones scholasticae quotidianae, Hymnus matutinus, A Prandio, In Adventu, A Nativitatis, Paschae, Fasti Puerorum", Gnomae sive sententiae morales, tyronibus literarum praescribendae, iuxta seriem alphabeticam collectae, et Germanicis verbis citra figuras expositae, Wrocław 1565. Zachowała się późniejsza edycja tego zbioru: Olomouc, Vědecká knihovna, sygn. 22.484.

53

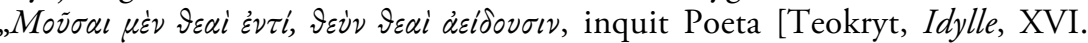

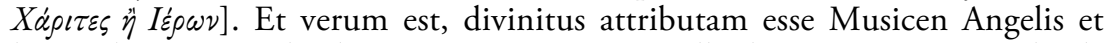
hominibus, ut Dei laudes praecipue sonent. Ac ille demum vere Musici laude dignus est, qui vim ingenii confert ad eam usum, ut Deum celebret. Id fecit, ut scis, Walteris Torgensis, qui ad caeteras laudes etiam istam addidit, ut vir sit pius et sanctus. Cumque Templis plurimas cantilenas composuerit, quas in sacris Congressibus quotidie audimus, gratiam ei profecto Ecclesiae debent, et gratitudinem nostram erga filium declaremus. Nunc igitur in hac dissipatione Academiarum, cum Pater hunc Ioh. Walterum, filium ad me miserit, ut quaeram ei aut scholam, aut paedagogiam, fretus et amicitia tua et erga Patrem benevolentia, misi eum ad te. Spero, tua ope inventurum esse $\pi \alpha \iota \delta \alpha \gamma \omega \gamma i \alpha \nu$ apud aliquem civem, aut in vicinia, aut certe aliis scholasticis adiungi poterit, quibus hospitium praebetis. Et huic adolescenti propter Patris merita debemus gratiam. Totam rem tuae fidei et prudentiae commendo. Volo et Vitum, cui vetus amicitia est cum Waltero, curare, ut filio prospiciatur. Civitas Vratislavia iam vestro exemplo Scholam instituit, et Iohannes Aurifaber gubernator est eius Scholae", List do Hieronima Besolda, 7 VII 1547 r., w: CR, vol. 6, s. 596-597.

54 Por. „In Colophone ac fastigio artium, musica et astronomia locantur. Age quid musica laudatius, elegantis ea harmoniae ratio, sive organicam, sive naturalem velis. Insignis utraque honore poematum, id quod alia sum acturus oratione. Plerisque gratior musica orbe artium aliarum, cum haec ad contemplationem 
W odróżnieniu od Lutra, który nadrzędną rolę muzyki uzasadniał argumentami natury teologicznej55, Melanchton koncentrował się na jej walorach stricte estetycznych, wielokrotnie pisząc o „słodyczy muzyki" ${ }^{56}$. Ciekawe, że ten wywiedziony z myśli Arystoksenosa topos $^{57}$ nie cieszył się zbytnim zainteresowaniem szesnastowiecznych reformatorów Kościoła, ale częsty był w piśmiennictwie ówczesnych teoretyków muzyki, którzy dostrzegali bliskie pokrewieństwo sztuki dźwięku z domeną trivium. Uznana za jedną ze sztuk retorycznych, muzyka jawi się jako zdecydowanie bardziej ludzka i w naturalny sposób bliższa człowiekowi ${ }^{58}$. Tak głęboko humanistyczna orienta-

pariter moresque conferant. Erigunt aliae ad coelestia mentes nostras, haec una coelo superos ad humana deducit, quo argumento veteres arbitror musica signa passim deum statuis appendisse, quasi illis dii conciliati nobiscum versentur. Confert moribus cum nulla res familiarior tranquillandis animantium affectibus. Scitis de Orphei lyra quid et quae Pythagoreae gentis instituta fuerint $\tilde{\omega} \delta a i ̈ \varsigma$

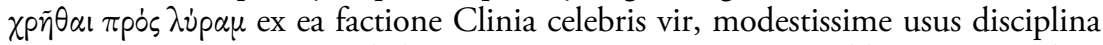
magistri, quoties animo turbabatur, quacunque caussa statim ad lyram properabat,

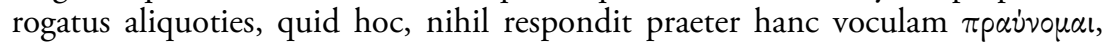
atque hi sunt proprie musarum soni, qui ad honestam vitae constitutionem, qui ad virtutem pertinent, succedunt musicae saltatoriae artes, Arcadum inventa, sed longior est res qua a nobis agi modo possit”, De artibus liberalibus oratio à Philippo Melanchthone Tubingae habita, [Hagenau 1518], Thüringer Universitäts- und Landesbibliothek, sygn. 4 Gl.IV,17(3), k. B 2 ver.; cyt. za: Melanchthons Werke in Auswahl, Bd. 3, hrsg. R. Nürnberger, Gütersloh 1961, s. 17.

55 Por. O. Söhngen, Theologische Grundlagen der Kirchenmusik, w: Leiturgia. Handbuch des evangelisches Gottesdienstes, Bd. 4: Die Musik des evangelisches Gottesdienstes, Kassel 1961, s. 66.

56 Por. „Nulla res enim, nullus cultus, magis ornat hominem, quam suavis oratio. Neque musica dulcior aut iucundior auribus, aut mente percipi ulla potest, quam aequabilis oratio, constans bonis verbis ac sententiis. Quare, si quem nulla voluptate talis oratio afficit, is longe a natura hominis degeneravit. Verissima sunt quae dico, et ostendere possem exempla hominum, qui haec studia contemnunt, quorum feri mores ostendunt, quantum ab humanitate absint. Ac nisi longum esset, ostenderem pluribus verbis haec studia faciendae orationis, mores reddere mitiores. Sed haec encomia artis, putant aliqui in scholis magis ex more dici, quam quod res ita se habeat. Verum olim inter ipsa negocia comperietis has laudes harum artium, non esse temere confictas. Ac ut redeam unde digressus sum, si tantum voluptati serviret elocutio, tamen non esset negligenda tam suavis musica", De Elocutione, w: CR, vol. 13, s. 460.

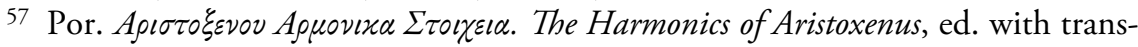
lation notes, introd. and index of words by H. S. Marcan, Oxford 1902, s. 236.

58 Por. J. M. Raley, Traversing Borders - Defining Boundaries. Cosmopolitan Harmonies and Confessional Theology in Georg Rhau's Liturgical Publications, „Sixteenth Century Journal”, 43, 2012, 4, s. 1088. 
cja myśli Melanchtona pozwala mu zresztą odnaleźć jej funkcję teologiczną: prowadzi zaś go do niej schrystianizowany arystotelesowski topos o harmonicznej budowie duszy ${ }^{59}$.

Niemiecki reformator rozwija te myśli w przedmowie do kolejnej edycji motetów Georga Rhaua, dobrze zresztą znanej w szesnastowiecznym Wrocławiu ${ }^{60}$. Użyteczność muzyki w kierowaniu duszy ludzkiej ku Bogu Melanchton wiąże z bliskością tej sztuki do natury człowieka, w szczególności zaś z tą cechą jego intelektu, która sprawia, że pamięta on o wydarzeniach zbawczych nie tylko w trakcie liturgii w kościele, ale także podczas nauki w szkole, przy okazji porządków domowych, w czasie pracy w ogrodzie i na polu ${ }^{61}$. Powszechna obec-

59 Por. Arystoteles, $O$ duszy, tł., wstęp, koment. i skorowidz P. Siwek, Warszawa 1972, 408a. Por. przedmowę do Selectae harmoniae quatuor vocum de passione Domini (Wittenberg 1538, Tenor, München, Bayerische Staatsbibliothek, sygn. 4 Mus.pr. 106\#Beibd.9, k. AA 1 rec.-ver.): „Non dubium est musicam generi humano praecipue datam esse, sacrorum causa, primum ut cantu, tanquam literis conservarentur et propagarentur oracula divinitus tradita, durabilior est enim numerorum et carminorum memoria. Deinde ut rectae sententiae magis penetrarent in animos, et ferirent ac moverent hominum pectora vehementibus. Est enim quaedam animae cum numeris et harmonia mirabilis cognatio, qua fit, ut avide accipiant animi harmonias et earum varietati respondeant varii motus in nobis. Sentiuntur haec non obscure, etsi ratio, cur fiant, non perspicitur, sed harmonicum quiddam est anima, et natura percipiens atque amans numeros atque harmoniam, ex quibus duobus existit ordinis cognitio, quo nihil est in omnibus rebus et in moribus pulchrius, quo animadverso, mens traducitur ad agnitionem Dei. [--] Hic praecipuus initio fuit musicae usus, ad hunc finem, cum divinitus tradita fit, est piae mentis, libenter eam hoc modo transferre, ut cantuum harmoniae respondeat illa viva in animis harmonia et piorum adfectuum concinnitas”.

60 Por. „Non dubium est praecipuam causam esse, cur musicae initia humano generi divinitus insista, et postea ars excitata sit, ut doctrina caeletis inclusa harmoniis et cantilenis laetius propagaretur, et longiori posteritatis memoriae traderetur. Nam et avide audiuntur blandae et dulces melodiae, et diuturna earum memoria est. Quare studia omnium piorum laudanda sunt, qui curaverunt olim, aut nunc curant suavibus et vere musicis cantilenis includi dicta prophetica et apostolica, et doctrinam salutarem de Christo, easque cantilenas spargi, ac tum in templis, tum in domestica oblectatione saepe repeti. Excitabatur Spiritus sanctus musica in Davide, et in Eliseo. Excitemus et nostras mentes cantu, ut maiore motu accipiant sententias horum carminum, et hoc studium canendi in aliis accendamus, ut rerum cogitatione, ad Christi agnitionem invitentur, et doctrina ad posteros etiam huius artis ope transmittatur", Officium (ut vocant) de Nativitate, Circumcisione, Epiphania Domini et Purificatione etc. tomus primus, Wittenberg 1545, Berlin, Staatsbibliothek Preussischer Kulturbesitz, sygn. Mus.ant.pract. R 460, k. A rec.

61 Por. „Naturale est homini in moerore, vel cantu lenire animi perturbationem, vel cogitatione sententiae, quae altius illapsa est animo propter melodiam, se 
ność muzyki w projektowanym przez Melanchtona pejzażu dźwiękowym Wrocławia (i jego podmiejskich okolic) prowadzi go do konkluzji o konieczności dbania o nauczanie muzyki ${ }^{62}$. Uznając muzykę za wehikuł oddziaływania Ewangelii, dochodzi do tych samych wniosków, co Luter ${ }^{63}$, osiąga je jednak nie na drodze spekulacji teologicznej, ale pragmatycznie uzasadnionego wywodu opartego na studiach nad ludzką naturą, które ongiś tak gorąco zalecał Moibanowi ${ }^{64}$.

Problem oddziaływania muzyki na człowieka Melanchton rozwija w przedmowie do popularnej na Śląsku agendy Lucasa Lossiusa. Posiłkując się argumentami zapożyczonymi od Arystotelesa, przytacza cele, którym może służyć sztuka dźwięku: rekreacji po pracy, dyscyplinowaniu obyczajów i kojeniu emocji ${ }^{65}$. Do tych trzech funkcji sztuki

erigere. Hoc exercitium salutare extinguunt aliqui nimis agrestes, qui nolunt adsuefieri populum ad dulces cantilenas, continentes doctrinam de Christo. Deinde metuendum est, ne citius in illis gentibus memoria doctrinae deleatur, ubi nec populus in templis, nec pueri in scholis, nec puellae in domesticis operis, aut in hortis, nec agricolae et messores in agris, nec equites in campis canunt prophetarum et apostolorum dicta. Saepe in peregrinationibus animadverti, quo in loco quomodo regantur Ecclesiae, tantum ex puellarum et aratorum cantu in agris, ac sicubi audivi sonantes pia carmina, vehementer gavisus sum, ac Deo gratias egi, propaganti memoriam Evangelii sui”, ibidem.

62

"Quanto magis exhilarari mentes non efferatas consentaneum est, cum audiunt in vernantibus hortis, in floridis pratis, in collibus herbidis, sanctarum virginum pios cantus, in quarum choris certum est una vagari et canere angelos Dei custodes horum piorum agminum. Quare non sequamur exemplum eorum, qui musicen negligunt, sed potius excitemus canendi studium, et exemplis et dulcedine carminum invitemus iuventutem et populum, ut se ad cogitationem de Deo, his musicis exercitiis accendant", ibidem, k. $A_{2}$ ver.

63 C. Krummacher, op. cit., s. 42-43.

64 Por. G. Bauch, Laurentius Corvinus.

65 Por. „Est et singulare Dei opus sensus Musices in homine et diiudicatio sonorum. Sic condita est natura, ut certos vocum gradus, metas, intervalla sentiat, suaviter adficiatur concinnis vocibus, offendatur contrariis: Imo quantum miraculum est aliis harmoniis alios seu cordis, seu spirituum motus excitari? Alexandrum certi cantus accendebat, ut arderet pugnandi cupiditate, flectebant alii rursus ad lenitatem et quietem. Quomodo intelligemus feriri animos his in aere motibus? Agnoscamus haec opera Dei, etiamsi causas non penitus perspicimus, ac Deum celebremus, qui magni usus causa naturae hominum hunc sensum Musices indidit. Aristoteles causas tres narrat: Primam, quia cum labor remissionibus indigeat, sint in natura honestae quaedam voluptates ordinatae, quibus defatigate vires reficiantur: Secundam esse inquit disciplinam, ut hac suavitate mores quasi ad concinnitatem flectantur, et fiant mitiores: Tertiam medicationem, ut maesticia, ira, et alii vehementiores motus leniantur", Psalmodia hoc est cantica sacra veteris Ecclesiae selecta, Wittenberg 1569, BUWr, sygn. 351352, k. A rec.-ver. 
dźwięku dodaje jeszcze jedną, teologiczną, wedle której muzyka jako medium treści ewangelicznych winna wzbudzać w człowieku wiarę za pomocą adekwatnej do treści melodii i harmonii ${ }^{66}$. Melanchton nie używa tu wprawdzie stosowanego przez współczesnych mu teoretyków terminu musica poetica ${ }^{67}$, jest jednak bardzo bliski temu właśnie rozumieniu sztuki dźwięku, które zawładnęło wyobraźnią późniejszych myślicieli. Twórców muzycznego baroku niemiecki reformator wyprzedza również refleksją na temat musica politica, uzupełniając teorię Platona o konstatacje łączące harmoniczne proporcje muzyki $\mathrm{z}$ ładem panującym w Kościele ${ }^{68}$.

Zainteresowanie Melanchtona muzyką nie ograniczało się bynajmniej do refleksji nad jej rolą w kulturze, ponieważ obejmowało sporą grupę jego tekstów przeznaczonych do wykonania muzycznego. Były to przede wszystkim łacińskie ody metryczne służące użytkowi

66 Por. „Haec vere, et sapienter dicta sunt: Sed non dubium est, praecipuam causam esse, ut doctrina de Deo carminibus compehensa propagari latius possit et diutius conservari. Citius enim arripiunt aures carmina, et harmoniae gratae penetrant altius in animos, et haerent in memoria tenacius. Et, ut suo quodam consilio Deus dissimilia genera adfectum condidit, ita voluit signa diversorum adfectuum in sonis esse. Hanc congruentiam sapientissime ordinatam esse agnoscamus, et ipsam Musicen, ut Dei opus ac donum veneremur, et, ut semper eius in sacris congressibus usus fuit, ita sciamus studiose hunc eius usum tuendum esse. Nec profecto quidquam dulcius est homini non monstroso, quam doctrina verbis recte illustrata, quae bonis harmoniis ad aures atque animos profertur. Et sensus testatur tali musica flecti animos tum ad dolores, cum audiunt querelas de nostris delictis, vel lugubres cantilenas de poenis, tum vero etiam leniri, cum audiunt dulciores melodias de Dei misericordia, et accendi ad invocationem. Haec cum ita sint, laudanda est voluntas artificum, qui tales melodias utiles docendis et flectendis animis edunt, et conservari ac transmitti ad posteros curant", ibidem, k. A ${ }_{3}$ ver. $-{ }_{4}$ rec.

67 Jak suponuje H. H. Eggebrecht, Heinrich Schütz musicus poeticus, Göttingen 1959, s. 33.

68 Por. „Mihi videtur concinnius accommodari ad Ecclesiam [--] dulcissima Harmonia Musica, quia concursus est dissimilium, honestorum et deformium, Ioseph, Davidis et Latronis in cruce. Sed hi sic concurrunt, ut sit proportio consentiens differentiarum, videlicet consonantia in agnitione Filii Dei ac fide. [--] In Ecclesia conspicitur Harmonica. Praecipue enim Deus Musicam generi humano ideo attribuit, ut cantu comprehenderetur, et aliis traderetur vera doctrina de essentia et voluntate Dei, simul ut memoria extenderetur, quia cantilenarum diuturnior est memoria, et ut adfectus doctrinae congruentes excitarentur, ideo semper in Templis verae Ecclesiae, et retenta est Musica, et culta est. Itaque et proportionem ipsam Harmonicam, voluit imaginem esse collectionis Ecclesiae ex concursu dissimilium numerorum, quorum tamen sit in fide consonantia”, Epistola complectens commendationem musicae, w: CR, vol. 10, s. 94-96. 
dydaktycznemu ${ }^{69}$, okolicznościowemu ${ }^{70}$ oraz teksty liturgiczne ${ }^{71}$. Część z nich trafiła do agend używanych na terenie Śląska ${ }^{72}$, inne zaś wielogłosowo opracowywali tacy kompozytorzy jak Hermann Finck, Gallus Dressler czy Leonhard Päminger ${ }^{73}$, który zresztą dedykował Melanchtonowi umuzycznienia kilku antyfon ${ }^{74}$, a jednej z nich nadał formę sześciogłosowego kanonu i zapisał w postaci grecko-łacińskiego rebusa $^{75}$. Melanchton musiał być więc obeznany $\mathrm{z}$ konceptualnymi formami notacji muzyki renesansu, ale także z praktyką gry na instrumentach, co dokumentują zachowane świadectwa $\mathrm{z}$ epoki ${ }^{76}$. Jego zaangażowanie $\mathrm{w}$ praktykę muzyczną potwierdza również wyrażona przezeń opinia na temat konieczności angażowania muzyków w proces dydaktyczny; przy okazji Schwartzerdt ujawnia swój własny gust muzyczny, zbliżony zresztą do Lutra ${ }^{77}$.

$69 \mathrm{~Np}$. Vos ad se pueri primis inviat ab annis, w: ibidem, s. 531.

70 Por. Amore flagrantissimo sponsam suam tenerrimam, w: ibidem, s. 627-628.

71 Por. Nil sum, nulla miser novi solatia, massam, w: ibidem, s. 628-629.

72 Por. In Festo [Visitationis BMV]. Alius Philip Melant. Iambicum dimetrum: Aeterne gratias, tibi dicamus omnes conditor, w: Psalmodia hoc est cantica, s. 217-218.

73 Najczęściej opracowywany był dystych Melanchtona Vespera iam venit, w: CR, vol. 10, s. 602; zob. L. Knopp, Philipp Melanchthon in der Musik seiner Zeit, „Musik und Kirche”, 67, 1997, 3, s. 170.

74 Por. Primus tomus ecclesiasticarum cantionum, quatuor, quinque, sex, et plurium vocum, a prima dominica Adventus, usque ad Passionem Domini et Salvatoris nostri Iesu Christi, Nürnberg 1573, BUWr, sygn. 50674 Muz., Discantus, s. 213-214: Antiphon de Apost. 4. voc anno 41. D. Philippo Melanchthoni in comitiis Ratisponensibus dedicata. Ecce ego mitto vos.

75 Por. Secundus tomus ecclesiasticarum cantionum, quatuor, quinque, sex, et plurium vocum, a Passione Domini et Salvatoris nostri Iesu Christi, usque ad primam dominicam post festum Trinitatis, Nürnberg 1573, München, Bayerische Staatsbibliothek, sygn. Mus.pr. 2013.211, Discantus, k. 100rec.-101rec.: De S. Philippo et Iacobo. Aliud. D. Philippo Melanchthoni compositum 6. Vocum, quarum tres notulis ac pausis, Reliquae vero literis ac dictis consonantes voces edunt. Philippe qui videt me.

76 Relacja Johannesa Mathesiusa, pastora kościoła w Joachimsthal, zob. J. Mathesius, Luthers Leben in Predigten, hrsg. G. Loesche, Prag 1906, s. 324: „Wenn nun D. Luther sich müde und heilig gearbeitet, war er am Tische fröhlich, ließ bisweilen eine Kantorei anrichten, auf eine Zeit im Beisein guter Leute sangen wir Didos letze Worte aus dem Virgil: Dulces exuviae: Herr Philippus tönte auch mit ein”.

77 Por. „Nam nulla est vel antiquior, vel accommodatior docenti pueros ratio, quam illa quae erotematis, seu interrogationibus commodis instituitur. Hoc nostrum consilium et voluntatem multi boni et docti viri semper probarunt, et iudicarunt nostram rationem docendi utilem esse scholis. Et sane, qui integros libros artium dicendi ad Academiarum magis usum, quam nostrarum trivialium scholarum institutionem puerilem conscriptos fusius, etiam pueris plane 
Podobieństwo muzycznego światopoglądu obydwu niemieckich reformatorów przysłoniły jednak istotne różnice doktrynalne, które doszły do głosu po edycji Confessio Augustana variata (1540). Rozdźwięk pomiędzy stronnictwem gnezjoluteranów a filipistów pogłębił się po śmierci Lutra i ogłoszeniu Interim saskiego (21 XII 1548), stanowiącego podejmowaną z inicjatywy Melanchtona próbę porozumienia z katolikami. Akcentowanie symbolizmu eucharystycznego zbliżało z kolei filipistów do reformacji kalwińskiej, co w środowiskach luterańskich wywołało niemało kontrowersjii ${ }^{78}$. Początkowo ominęły one Wrocław, uznawany za najspokojniejsze pod względem konfesyjnym miasto Rzeszy ${ }^{79}$, później jednak dały się odczuć również nad Odrą, czego świadectwem jest jeden z ostatnich listów Schwartzerdta do elit miejskich Wrocławia ${ }^{80}$. Pozostawały one jednak życzliwe wobec autorytetu Melanchtona nawet po jego śmierci, o czym świadczy niesłabnąca obecność jego podręczników we wrocławskich prasach drukarskich i w programie nauczania tamtejszych gimnazjów ${ }^{81}$.

Spadkobiercą tradycji dydaktycznej Melanchtona był kolejny rektor elżbietańskiego gimnazjum, Peter Vincentius, który w $1570 \mathrm{r}$. opracował nową ustawę szkolną, nawiązującą do modelu kształcenia wittenberskiego preceptora. Odwoływał się w niej do tekstów źródłowych zebranych przez Melanchtona, zredagowanego przezeń katechizmu, a także umieszczonego we wcześniejszej ustawie systemu

rudibus proponendos esse censent, non minus illi stulte facere videntur, quam si citharoedum aliquem, tyroni, quem nuper is instituendum fidibus susceperit, difficilimas cantilenas, quas Mutetas vocant, vel Iosquini, vel alterius excellentis Musici, iubeant proponere, quas ille rudis adhuc omnium discipulus, subito ludendo quasi arriperet, priusquam aut ipsa nomina, aut ordinem chordarum et claviculorum cytharae exacte habuerit cognita"; Erotemata dialecticae et rhetoricae Philippi Melanchtonis et praeceptionum Erasmi Roterodami de utraque copia verborum et rerum, iam primum ad usum scholarum (quas vocant triviales) breviter selecta et contracta per Lucam Lossium Luneburgensem ediscendi, Leipzig 1563, BN, sygn. SD XVL.O.1090 adl., k. A 3 ver. ${ }_{4}$ rec.

78 Por. J. Delumeau, op. cit., s. 181-182.

79 „S. D. Venerande Adame et amice carissime. Toto pectore gratias ago filio Dei, domino nostro Iesu Christo, quod ita gubernavit Ecclesiam in inclyta urbe Vratislavia, ut dissidia dogmatum non turbaverent piorum invocationem annos iam triginta. Nec ulla Ecclesia in Germania fuit tranquillior. [--] Gaudeo tibi locum in Ecclesia Vratislaviensi tributum esse, et filium Dei oro, qui sedet ad dextram aeterni patris, ut det dona hominibus, ut nos quoque gubernet", List do Adama Cureusa, 19 X 1552 r., w: CR, vol. 7, s. 1113-1114.

80 List do Johanna Morenberga, 31 VII 1559 r., w: CR, vol. 9, s. 847.

81 Por. G. Bauch, Geschichte des Breslauer Schulwesens, s. 199-202, 292-304. 
nauczania muzycznego opartego na tradycyjnie łacińskich formach liturgii ${ }^{82}$. Pod względem doktryny teologicznej personel wrocławskich kościołów był wprawdzie coraz częściej obligowany do składania deklaracji lojalności wobec pierwotnej wersji Confessio Augustana, ci zaś, którzy uczynić tego nie chcieli, byli piętnowani jako kryptokalwiniści i zmuszani do zmiany zawodu ${ }^{83}$. Konfesjonalizacja wrocławskich instytucji kościelnych w niewielkiej mierze dotknęła jednak instytucji szkolnych, a te na początku XVII w. nadal kierowały się ideałami humanistycznymi, szerzonymi przez kolejne pokolenia spadkobierców myśli Melanchtona.

Zaproponowana przezeń metodyka szkolna była głównym punktem odniesienia dla programu nauczania takich wrocławskich nauczycieli jak: Nicolaus Steinberg, David Rhenisch, Andreas von Höckelshoven, Martin Helwig, Georg Seidel i Elias Major, którzy przygotowywali do druku kolejne edycje podręczników Melanchtona i na ich podstawie prowadzili swoje zajęcia $\mathrm{w}$ gimnazjach miasta ${ }^{84}$. Pielęgnowali również żywą pamięć o reformatorze (np. w stulecie jego śmierci ${ }^{85}$ ); przede wszystkim kontynuowali jednak wszechstronny program nauczania, obejmujący kształcenie nie tylko w zakresie łaciny, ale także praktyki teatralnej ${ }^{86}$ oraz muzycznej ${ }^{87}$. Wracali w ten sposób do źródeł wskazanych przez pierwsze pokolenia luminarzy wrocławskich humanistów, za którymi podążać nakazywał praeceptor Germaniae.

O tym, jak zachęty te wdrażali w życie animatorzy kultury muzycznej siedemnastowiecznego Wrocławia, dobitnie świadczy unikatowy zbiór muzykaliów kolekcjonowany przez Daniela Sartoriusa, nauczyciela gimnazjum św. Elżbiety ${ }^{88}$. Zgromadzony tam repertuar służył

82 Ibidem, s. 223.

83 Por. K. Garber, op. cit., s. 57, 250.

84 G. Bauch, Geschichte des Breslauer Schulwesens, s. 292-313.

85 Por. Saecularem Melanchthoniani Diei Emortualis, memoriam in Gymnasio Vratislaviensi Elisabethano a. d. IV Non. Majas Anno Chr. CID ID CLX horis a prima pomeridianis recolendam indicit M. Elias Major Rector, Wrocław 1660, BSPK, sygn. Ah 16124.

86 Por. Das Breslauer Schultheater im 17. und 18. Jahrhundert. Einladungsschriften $z u$ den Schulactus und Szenare zu den Aufführungen förmlicher Comödien an den protestantischen Gymnasien, hrsg. K. Gajek, Tübingen 1994.

87 Zob. T. Jeż, Z pamiętników muzykalnego humanisty. „Schreibkalender” Eliasa Maiora (1588-1669) jako źródto do historii kultury muzycznej Wroctawia, OiRwP, 61, 2017, s. 165-193.

88 Zob. idem, Danielis Sartorii musicalia wratislaviensia, Warszawa 2017 (Fontes Musicae in Polonia, seria A, t. 1). 
jego uczniom, co sugerują liczne odręczne dopiski i rękopiśmienne kopie tego repertuaru sporządzone ręką Sartoriusa. Po jego śmierci kolekcja nie została włączona do zasobów służących liturgii wrocławskiej fary, scalono ją zaś ze słynnym zbiorem Thomasa Rehdigera ${ }^{89}$. Był on wittenberskim uczniem Melanchtona, a jego humanistyczne poglądy na styl muzyki podzielał Daniel Sartorius. W kolekcji Rehdigera znajdujemy dzieła najwybitniejszych kompozytorów włoskiego baroku, reprezentujących nie tylko utwory liturgiczne, ale i madrygały, utwory dramatyczne oraz instrumentalne. Wspólnym mianownikiem tych gatunków jest kategoria musica poetica, która zadomowiła się w historii muzyki od czasów Nicolausa Listeniusa, jeszcze jednego ucznia Melanchtona ${ }^{90}$.

\section{Bibliografia}

\section{Źródła}

Ad Clariss. Principem, eundemque Reverendiss. D. D. Balthasarem Episcopum Vratislaviens: etc. Epistola Gratulatoria. Autore Ambrosio Moibano Parocho Vratislavien: Adiecta est et Epistola Phil. Melan. ad eundem Episcopum, Wrocław 1541, BUWr, sygn. 303030

Catechismi capita decem: primum quibusdam thematis deinde etiam colloquiis puerilibus illustrata, iuventuti Wratislaviensi proposita. Ambrosius Moibanus. Accessit et puellae cuiusdam oratiuncula in nativitate Ihesu Christi publice dicta. Cum prefatione Phil. Mel., Wittenberg 1538, BUWr, sygn. 301174

De artibus liberalibus oratio à Philippo Melanchthone Tubingae habita, [Hagenau 1518], Thüringer Universitäts- und Landesbibliothek, sygn. 4 Gl.IV,17(3)

Elementa latinae grammatices ab ipso autore recognita. Philip. Melancht., Wrocław 1539, BUWr, sygn. 372172

Erasmi Roterodami libellus de constructione octo partium orationis ex Britannia super huc perlatus: ut ex eo pueri bonis in literis optimo compendio bonum profectum faciant, Coloniae 1515, Den Haag, Koninklijke Bibliotek, sygn. 226 E 65

89 Szerzej na ten temat zob. J. Baecker, Thomas Rehdiger, der Mann und sein Werk. Ein Beitrag zur Geschichte des geistigen Lebens im 16. Jahrhundert. Inaugural-Dissertation zur Erlangung der Doktorwürde der Hohen Philosophischen Fakultät der Schlesischen Friedrich Wilhelms-Universität zu Breslau, Breslau 1921.

90 Zob. Musica Nicolai Listenii, ab authore denuo recognita, multisque novis regulis et exemplis adaucta, Wittenberg 1537, Freiburg, Universitätsbibliothek, sygn. 62909. 
Erotemata dialecticae et rhetoricae Philippi Melanchtonis et praeceptionum Erasmi Roterodami de utraque copia verborum et rerum, iam primum ad usum scholarum (quas vocant triviales) breviter selecta et contracta per Lucam Lossium Luneburgensem ediscendi, Leipzig 1563, BN, sygn. SD XVL.O.1090 adl.

Erotemata musicae practice ad captum puerilem formata, Virgilio Haug autore, Wrocław 1541, Bruksela, Bibliothèque royale de Belgique, sygn. A- $\mathrm{G}_{8}$

Gnomae sive sententiae morales, tyronibus literarum praescribendae, iuxta seriem alphabeticam collectae, et Germanicis verbis citra figuras expositae, Wrocław 1565, Olomouc, Vědecká knihovna, sygn. 22.484

Musica Nicolai Listenii, ab authore denuo recognita, multisque novis regulis et exemplis adaucta, Wittenberg 1537, Freiburg, Universitätsbibliothek, sygn. 62909

Officium (ut vocant) de Nativitate, Circumcisione, Epiphania Domini et Purificatione etc. tomus primus, Wittenberg 1545, Berlin, Staatsbibliothek Preussischer Kulturbesitz, sygn. Mus.ant.pract. R 460

Oratio Philippi Melanchtonis dicta ab ipso cum decerneretur gradus magisterii D. Andreae Winclero Vratisla. et alijs quibusdam bonis et doctis viris anno M.D. XXXV. die Aprilis 14, Strasbourg [1535], Jena, Thüringer Universitäts- und Landesbibliothek, sygn. 8 Phil.IX,24

P. Terentii comoediae, iuxta doctissimorum virorum recognitionem, quam diligentissimae excusae. [--] Accesserunt praeterea argumenta. Philippi Melanch. et Rivij castigationes, scholia cum omnium fere scenarum argumentis, quae prolixi commentarij vice esse possunt, Wrocław 1540, BUWr, sygn. 373119

Paedia artis grammatice Ambrosij Moibani opera, in compendie formam redacta ac denuo recognita locupletataque cuius praesidio, pueri latinae linguae rudimenta facilius condiscant, Leipzig 1522, BUWr, sygn. 442131

Primus tomus ecclesiasticarum cantionum, quatuor, quinque, sex, et plurium vocum, a prima dominica Adventus, usque ad Passionem Domini et Salvatoris nostri Iesu Christi, Nürnberg 1573, BUWr, sygn. 50674 Muz.

Psalmodia hoc est cantica sacra veteris Ecclesiae selecta, Wittenberg 1569, BUWr, sygn. 351352

Saecularem Melanchthoniani Diei Emortualis, memoriam in Gymnasio Vratislaviensi Elisabethano a. d. IV Non. Majas Anno Chr. CID ID CLX horis a prima pomeridianis recolendam indicit $M$. Elias Major Rector, Wrocław 1660, Berlin, Staatsbibliothek Preussischer Kulturbesitz, sygn. Ah 16124

Secundus tomus ecclesiasticarum cantionum, quatuor, quinque, sex, et plurium vocum, a Passione Domini et Salvatoris nostri Iesu Christi, usque ad primam dominicam post festum Trinitatis, Nürnberg 1573, München, Bayerische Staatsbibliothek, sygn. Mus.pr. 2013.211

Selectae harmoniae quatuor vocum de passione Domini, Wittenberg 1538, München, Bayerische Staatsbibliothek, sygn. 4 Mus.pr. 106\#Beibd.9 
Selectiores Horatiani Operis Odea ad formandos mores tum cognitu utiles, tum perquem iucundae. Adiecta sunt aliquot pia epigrammata ex varijs poetis Christianis, Wrocław 1542, BUWr, sygn. 336073

Syntaxis Philippi Melanchtonis emendata et aucta ab autore, Wrocław 1540, BUWr, sygn. 372174

Unterricht der Visitatoren, an die Pfarrherren im Kurfürstenthum zu Sachssen, Wittenberg 1528, Jena, Thüringer Universitäts- und Landesbibliothek, sygn. HZ: 8 MS 30942(5)

\section{Opracowania}

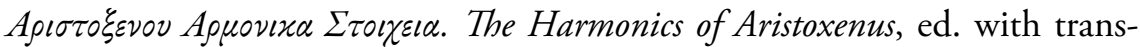
lation notes, introd. and index of words by H. S. Marcan, Oxford 1902 Arystoteles, $O$ duszy, tł., wstęp, koment. i skorowidz P. Siwek, Warszawa 1972 Baecker J., Thomas Rehdiger, der Mann und sein Werk. Ein Beitrag zur Geschichte des geistigen Lebens im 16. Jahrhundert. Inaugural-Dissertation zur Erlangung der Doktorwürde der Hohen Philosophischen Fakultät der Schlesischen Friedrich Wilhelms-Universität zu Breslau, Breslau 1921

Bauch G., Geschichte des Breslauer Schulwesens in der Zeit der Reformation, Breslau 1911 (Codex Diplomaticus Silesiae, Bd. 26)

Bauch G., Laurentius Corvinus, der Breslauer Stadtschreiber und Humanist. Sein Leben und seine Schriften, „Zeitschrift des Vereins für Geschichte und Alterthum Schlesiens", 17, 1883, s. 230-302

Bohn E., Die musikalischen Handschriften des XVI. und XVII. Jahrhunderts in der Stadtbibliothek zu Breslau, Breslau 1890

Das Breslauer Schultheater im 17. und 18. Jahrhundert. Einladungsschriften $z u$ den Schulactus und Szenare zu den Aufführungen förmlicher Comödien an den protestantischen Gymnasien, hrsg. K. Gajek, Tübingen 1994

Burbianka M., Andrzej Winkler - drukarz wroctawski XVI wieku, „Roczniki Biblioteczne", 4, 1960, s. 329-445, 636-638

Delumeau J., Reformy chrześcijaństwa w XVI i XVII w., t. 1: Narodziny i rozwój reformy protestanckiej, tł. J. M. Kłoczowski, Warszawa 1986

Eggebrecht H. H., Heinrich Schütz musicus poeticus, Göttingen 1959

Fleischer M. P., Die Konkordienformel in Schlesien, „Jahrbuch für schlesische Kirchengeschichte", 58, 1979, s. 50-83

Garber K., Das alte Breslau. Kulturgeschichte einer geistigen Metropole, Köln-Weimar-Wien 2014

Harasimowicz J., Ślaski luteranizm wieku reformacji - próba charakterystyki, „Śląski Kwartalnik Historyczny Sobótka”, 39, 1984, 4, s. 493-516

Jeż T., Danielis Sartorii musicalia wratislaviensia, Warszawa 2017 (Fontes Musicae in Polonia, seria A, t. 1)

Jeż T., Eacińska twórczość muzyczna w ewangelickim Wroctawiu. Kwestia trwatości tradycji w czasach przemian konfesyjnych, „Barok. Historia - Literatura - Sztuka", 11, 2004, 2 (22), s. 185-205 
Jeż T., Z pamiętników muzykalnego humanisty. „Schreibkalender” Eliasa Maiora (1588-1669) jako źródto do historii kultury muzycznej Wroctawia, OiRwP, 61, 2017, s. $165-193$

Karski K., Filip Melanchton w 500. rocznice urodzin, „Myśl Protestancka”, 4, 1997, s. 32-38

Knopp L., Philipp Melanchthon in der Musik seiner Zeit, „Musik und Kirche”, 67, 1997, 3, s. 165-171

Krummacher C., Musik als praxis pietatis. Zum Selbstverständnis evangelischer Kirchenmusik, Göttingen 1994

Mathesius J., Luthers Leben in Predigten, hrsg. G. Loesche, Prag 1906

Modlińska-Piekarz A., Doktryna i polityka w tacińskiej poezji biblijnej ślaskich uczniów Filipa Melanchtona, OiRwP, 61, 2017, s. 195-233

Philippi Melanchthonis opera quae supersunt omnia, hrsg. C. G. Bretschneider, Halle 1834-1846 (Corpus Reformatorum, vol. 1-13)

Pol N., Jahrbücher der Stadt Breslau, Bd. 3, Breslau 1819

Raley J. M., Traversing Borders - Defining Boundaries. Cosmopolitan Harmonies and Confessional Theology in Georg Rhau's Liturgical Publications, „Sixteenth Century Journal”, 43, 2012, 4, s. 1079-1105

Sander H.-A., Beiträge zur Geschichte des lutherischen Gottesdienstes und der Kirchenmusik in Breslau. Die lateinischen Haupt- und Nebengottesdienste im 16. und 17. Jahrhundert, Breslau 1937 (Breslauer Studien zur Musikwissenschaft, Bd. 1)

Söhngen O., Theologische Grundlagen der Kirchenmusik, w: Leiturgia. Handbuch des evangelisches Gottesdienstes, Bd. 4: Die Musik des evangelisches Gottesdienstes, Kassel 1961, s. 1-267

Tazbir J., Filip Melanchton w pamięci Polaków, OiRwP, 40, 1996, s. 5-16

\section{Filip Melanchton's Thought on Music and Its Role in Shaping the Musical Culture of Humanistic Breslau}

The preserved writings of Philip Melanchthon addressed to the animators of religious life in Evangelical Breslau (Wrocław) and the superiors of schools operating in the city indicate the German reformer's active involvement in shaping the musical culture of the metropolis on the Oder. The presence of music in the religious formation and school education was justified by the rhetorical qualities of the art of sound, which made it possible to influence the intellect and emotions of the faithful and students. Praeceptor Germaniae perceived the particular usefulness of music in its very nature, related and similar to the nature of the human soul. The humanistically oriented pragmatism of his argumentation marks its presence both in his letters and his theoretical writings as well as normative acts regulating the functioning of 
the ecclesiastical and didactic institutions of Breslau. The doctrinal differences between Luther's uncompromisingness and Melanchthon's irenic approach somewhat limited the reception of the latter's thought. However, in a culture shaped by the heirs of his tradition, primarily concentrated within the circles of the city's pedagogical elite, it nevertheless enjoyed an unflagging reception for many decades after his death.

Tomasz Jeż - studiował muzykologię w Warszawie, Getyndze i Berlinie. Po promocji doktorskiej (2002) zatrudniony w Instytucie Muzykologii Uniwersytetu Warszawskiego, aktualnie na stanowisku profesora uczelni. W ramach programu „Kolumb” Fundacji na rzecz Nauki Polskiej odbył staż naukowy w Rzymie (2007/2008). Jest autorem czterech książek i 70 artykułów, poświęconych zagadnieniom źródłoznawczym i ideowym aspektom kultury muzycznej. Jego głównym polem badań jest kultura muzyczna Śląska i Rzeczypospolitej Obojga Narodów w XVI-XVIII w.

Tomasz Jeż - studied musicology in Warsaw, Göttingen and Berlin. After his doctoral promotion (2002), he was employed at the Institute of Musicology of the University of Warsaw; currently he holds the position of professor at the university. As part of the KOLUMB programme of the Foundation for Polish Science, he completed an internship in Rome (2007/2008). He is the author of four books and seventy articles, devoted to sources and ideological aspects of musical culture. His main field of research is the musical culture of Silesia and the Polish-Lithuanian Commonwealth in the sixteenth-eighteenth centuries.

E-mail: tomasz.jez@uw.edu.pl 